\title{
Prevalence and prognostic relevance of myocardial inflammation and cardiotropic viruses in non-ischemic dilated cardiomyopathy
}

\author{
Ieva Kažukauskienè ${ }^{1}$, Vaida Baltrūniené ${ }^{1}$, Artūras Jakubauskas ${ }^{2}$, \\ Edvardas Žurauskas ${ }^{1}$, Vytė Valerija Maneikienè ${ }^{3}$, Dainius Daunoravičius ${ }^{4}$, \\ Jelena Čelutkienè ${ }^{3}$, Kęstutis Ručinskas ${ }^{3}$, Virginija Grabauskiene் $\dot{e}^{1,3}$ \\ ${ }^{1}$ Department of Pathology, Forensic Medicine and Pharmacology, \\ Faculty of Medicine, Vilnius University, Vilnius, Lithuania \\ ${ }^{2}$ Hematology, Oncology and Transfusion Medicine Center, \\ Vilnius University Hospital Santaros Klinikos, Vilnius, Lithuania \\ ${ }^{3}$ Clinic of Cardiac and Vascular Diseases, Institute of Clinical Medicine, \\ Faculty of Medicine, Vilnius University, Vilnius, Lithuania \\ ${ }^{4}$ Clinicus Vilnius, Lithuania
}

\begin{abstract}
Background: Non-ischemic dilated cardiomyopathy (DCM) is a heterogeneous disease with a spectrum of etiological factors. However, subsets of the disease are not well-characterized with respect to these factors. The aim of this study was to evaluate the prevalence of myocardial inflammation and cardiotropic viruses in DCM patients and their impact on clinical outcome.

Methods: Fifty-seven patients with DCM underwent endomyocardial biopsy between 2010 and 2013. Biopsies were analyzed by polymerase chain reaction (PCR) for the presence of cardiotropic viruses, and inflammatory cell infiltration was assessed by immunohistochemistry. During a 5-year follow-up, 27 (47\%) patients reached the composite outcome measure: heart transplantation, left ventricle assist device implantation or cardiovascular-related death.

Results: Thirty-one (54\%) patients had myocardial inflammation and cardiotropic viruses were detected in 29 (52\%). The most frequent viruses were parvovirus B19 and human herpesvirus type-6. Four specific sub-groups were distinguished by PCR and immunohistochemistry: virus-positive (chronic) myocarditis, autoreactive inflammatory DCM, viral DCM, non-inflammatory DCM. The presence of a viral genome in myocardium or diagnosis of inflammatory DCM did not predict the outcome of composite outcome measures $(p>0.05)$. However, univariate Cox regression and survival function estimation revealed an association between inflammation by a high number of T-cells and poor prognosis.

Conclusions: This study has shown that two markers - cardiotropic viruses and myocardial inflammation - are prevalent among DCM patients. They are also helpful in identifying sub-groups of DCM. An increased number of T-lymphocytes in the myocardium is a predictor of poor mid-term and long-term prognosis. (Cardiol J 2022; 29, 3: 441-453)
\end{abstract}

Key words: dilated cardiomyopathy, chronic heart failure, myocardial inflammation, viruses, prognosis

Address for correspondence: Ieva Kažukauskienė, MD, Department of Pathology, Forensic Medicine and Pharmacology, Faculty of Medicine, Vilnius University, M. K. Ciurlionio 21, LT-03101 Vilnius, Lithuania, tel: +37052398728, e-mail: ieva.zasytyte@gmail.com

Received: 1.11.2019 Accepted: 11.05.2020 Early publication date: 17.06.2020

This article is available in open access under Creative Common Attribution-Non-Commercial-No Derivatives 4.0 International (CC BY-NC-ND 4.0) license, allowing to download articles and share them with others as long as they credit the authors and the publisher, but without permission to change them in any way or use them commercially. 


\section{Introduction}

Non-ischemic dilated cardiomyopathy (DCM) is a chronic heart disease. It presents with left ventricle (LV) dilatation and impaired ventricle function (left or both ventricles), which is not caused by coronary artery disease or abnormal loading conditions [1]. DCM is a heterogeneous disease with a spectrum of etiologic factors such as infectious agents, genetic abnormalities, autoimmune mechanisms, drugs, and toxins [2]. DCM causes heart failure, leading to heart transplantation or death [3].

Over the past few decades, the definition of DCM has developed [1, 4-6]. Endomyocardial biopsy, analyzed by immunohistochemistry and viral polymerase chain reaction (PCR), became an essential procedure for diagnosing the cause of DCM $[1,7,8]$. Consequently, cardiotropic viruses are recognized as a crucial etiologic factor of heart failure and are found in the myocardium of up to $67 \%$ of DCM patients $[10,11]$. The data concerning the impact of the presence of cardiotropic viruses on clinical significance and prognosis remains under debate $[12,13]$.

Diagnostic criteria for inflammation in the myocardium were updated several times $[1,4,5,9]$. Myocardial inflammation, confirmed by endomyocardial biopsy, is also known as a significant causal factor, and is responsible for progression of LV dilatation [14-17]. However, the prognostic role of myocardial inflammation on clinical outcome varies in different studies due to diverse diagnostic criteria $[12,18-21]$. The latest definition of myocardial inflammation was endorsed by the European Society of Cardiology (ESC) Working Group on Myocardial and Pericardial Diseases [1]. However, there is a shortage of data, which demonstrate the prognostic relevance of myocardial inflammation defined by this criterion. In addition, immunohistochemistry and viral PCR are used to characterize etiopathogenetic subsets of DCM patients, but prospective data are lacking for these subsets. Thus, the clinical value of research of etiopathogenetic factors may be of paramount importance to prognosis assessment and may help to further the development of treatment strategies.

The aim of this study was to use immunohistochemistry and PCR - to evaluate the prevalence of myocardial inflammation and cardiotropic viruses - in DCM patients. Further, to investigate their impact on the clinical outcome; and to clarify the impact of different myocardial inflammatory cells on mid-term and long-term prognosis.

\section{Methods}

\section{Study population. Inclusion and exclusion criteria}

A prospective cohort study was done in our center between January 2010 and December 2013. 57 patients admitted to this institution with heart failure and reduced LV ejection fraction (LVEF) (with unknown etiology of LV dilatation) for diagnostic evaluation were enrolled. Inclusion criteria were clinical signs and symptoms of heart failure, accompanied by echocardiographic evidence of LV dilatation (LV end-diastolic diameter [LVEDD] $>117 \%$ of the predicted value, corrected for age and body surface area [ $>2$ standard deviations] of the predicted normal limit $+5 \%)$ and reduced $(<45 \%)$ LVEF $[22,23]$.

Exclusion criteria were: 1) Significant coronary artery disease, defined as at least $50 \%$ proximal stenosis of a coronary artery or a history of myocardial infarction; 2) Known causes of heart failure, such as primary valvular or heart muscle disease, hypertensive heart disease, endocrine disease, advanced renal insufficiency, drug or alcohol abuse; 3) Acute myocarditis (new-onset symptoms during the past 3 months) or acute myocardial infarction suspected by clinical presentation or in diagnostic testing.

All patients provided written informed consent. Ethical approval was obtained from the local Lithuanian Bioethics Committee (license numbers 158200-09-382-103; 158200-382-PP1-23; and 158200-17-891-413).

All patients were treated according to the ESC guidelines [24, 25]. At the time of inclusion, none of the patients were treated with inotropic agents. Specific etiology-directed treatment was not administered.

\section{Medical examinations}

All patients underwent a medical interview, physical examination, and routine laboratory studies. Additionally, the proinflammatory serum cytokine interleukin-6 (IL-6) was tested as described elsewhere [26].

Echocardiography was performed for all patients to obtain conventional echocardiographic parameters. Cardiac magnetic resonance with late gadolinium enhancement was performed for 33 patients.

Mandatory investigations included coronary angiography to exclude coronary artery disease, right heart catheterization for hemodynamic evaluation. During the same procedures, right ventricle 
endomyocardial biopsy was performed for the immunohistochemical evaluation and the detection of viruses by PCR. Three endomyocardial biopsy procedures were discontinued because of complications (arrhythmias or right ventricular perforation). Due to the lack of biopsy samples, PCR was performed for two of the abovementioned patients and immunohistochemical analysis for one.

\section{Histological and immunohistochemical assessment}

Storage of the endomyocardial biopsy samples, and histological and immunohistochemical analyses were performed as described previously [26]. In brief, we detected antibodies (Santa Cruz Biotechnology, Inc.) against: T-lymphocyte CD3 (DAKO A0452 Rabbit 1, Hamburg, Germany), active-memory T-lymphocyte CD45Ro (DAKO Hamburg), macrophage CD68 (DAKO M0876 Mouse 1, Hamburg), T-helper cell CD4 (DAKO Hamburg, Germany), intracellular adhesion molecule-1 (ICAM-1) CD54 (NovocastraTM Lyophilized Mouse Monoclonal Antibody CD54 Clone 23G12), and MHC class II cell surface receptor HLA-DR (DAKO Hamburg, Germany). Positive cells were registered by an experienced pathologist and expressed as the number of cells per $\mathrm{mm}^{2}$. Myocardial inflammation was diagnosed according to the criterion established by the ESC Working Group on Myocardial and Pericardial Diseases. This criterion is immunohistochemical detection of significant focal or diffuse cellular infiltration in the endomyocardial biopsy ( $\geq 14$ leucocytes $/ \mathrm{mm}^{2}$, including up to 4 monocytes $/ \mathrm{mm}^{2}$ with the presence of CD3 positive T-lymphocytes $\geq 7$ cells $/ \mathrm{mm}^{2}$ ) [1] Inflammatory endothelial activation was diagnosed if immunohistochemical analysis revealed $\geq 3$ cells expressing adhesion molecules, i.e., ICAM-1 (CD54) and/or HLA-DR [27].

\section{Detection of viral genomes}

Genomic DNA and total RNA were extracted simultaneously using the ZR-Duet DNA/RNA Miniprep kit (Zymo Research, Irvine, CA, USA). RNA $(1 \mu \mathrm{g})$ was reverse transcribed in $20 \mu \mathrm{L}$ reaction volumes using random hexamers and the First Strand cDNA Synthesis Kit (Thermo Fisher Scientific, Vilnius, Lithuania) according to the vendor's recommendations and diluted up to $100 \mu \mathrm{L}$ with deionized water after the reaction.

Nested PCR primers for the detection of adenovirus [28], herpes simplex viruses 1 and 2, varicella-zoster virus (VZV), cytomegalovirus
Table 1. Primers for detection of human herpes virus 6 (HHV6), Kirsten rat sarcoma viral oncogene homolog (KRAS) and ubiquitin C (UBC).

\begin{tabular}{|c|c|}
\hline Primer & Sequence $\left(5^{\prime}-3^{\prime}\right)$ \\
\hline $\begin{array}{l}\text { HHV6-N1 } \\
\text { Forward }\end{array}$ & ACCCGAGAGATGATTTTGCGTG \\
\hline $\begin{array}{l}\text { HHV6-N1 } \\
\text { Reverse }\end{array}$ & GCAGAAGACAGCAGCGAGATAG \\
\hline $\begin{array}{l}\text { HHV6-N2 } \\
\text { Forward }\end{array}$ & CATAGCAACCTTTTCTAGCTTTGAC \\
\hline $\begin{array}{l}\text { HHV6-N2 } \\
\text { Reverse }\end{array}$ & TCTATAACATAAATGACCCCTGGGA \\
\hline $\begin{array}{l}\text { UBC-N1 } \\
\text { Forward }\end{array}$ & TTCTTTCCAGAGAGCCGAAC \\
\hline $\begin{array}{l}\text { UBC-N1 } \\
\text { Reverse }\end{array}$ & СССАТСTTCCAGСTGTTTTC \\
\hline $\begin{array}{l}\text { UBC-N2 } \\
\text { Forward }\end{array}$ & TGGGTCGCAGTTCTTGTTTG \\
\hline $\begin{array}{l}\text { UBC-N2 } \\
\text { Reverse }\end{array}$ & ССTTCСTTATCTTGGATCTTTGCC \\
\hline $\begin{array}{l}\text { KRAS-N1 } \\
\text { Forward }\end{array}$ & CTTTGGAGCAGGAACAATGTCT \\
\hline $\begin{array}{l}\text { KRAS-N2 } \\
\text { Forward }\end{array}$ & AATCCAGACTGTGTTTCTCCСТ \\
\hline $\begin{array}{l}\text { KRAS-N1/N2 } \\
\text { Reverse }\end{array}$ & TACACAAAGAAAGCССТСССС \\
\hline
\end{tabular}

(CMV), parvovirus B19 (B19V), Epstein-Barr virus (EBV), hepatitis $\mathrm{C}$ virus ( $\mathrm{HCV}$ ), enterovirus (EV), and rubella virus [29] are described elsewhere. Primer sequences for the nested PCR of human herpes virus 6 (HHV-6, GenBank accession no. NC001664.2 and NC000898.1); Kirsten rat sarcoma viral oncogene homolog (KRAS, GenBank accession no. NM033360); and ubiquitin C (UBC, GenBank accession no. NM021009) are presented in Table 1. Forward primers for the second PCR step (N2Fw) were labeled with 6-carboxyfluorescein at the 5' end. All primers were synthesized by the Metabion Company (Martinsried, Germany).

All PCRs were run on a TProfessional Standard thermocycler (Biometra, Göttingen, Germany), as described by Allard et al. [28]. KRAS and UBC detection was used to validate the extraction of nucleic acids and was performed in parallel according to the conditions for viral DNA and RNR, respectively. Final PCR products were diluted 10 -fold and sized by capillary electrophoresis on a Genetic Analyzer 3130xl, using GeneScan 600 LIZ $^{\mathrm{TM}}$ Size Standard and Gene Mapper Software v4.1 (Applied Biosystems, Foster City, CA, USA). For positive results, the genomic DNA or RNR 
specimens from peripheral blood samples were also tested to exclude contamination.

\section{Follow-up}

All patients were followed-up for 5 years after the endomyocardial biopsy. The composite outcome measures were composite and combined three outcomes: cardiovascular death, LV assist device implantation, or heart transplantation. The time of the first event was included in the analysis. Followup events were confirmed by medical records or telephone interview with the patients' families.

\section{Statistical analysis}

Data management and analysis were performed using the $\mathrm{R}$ studio package (3.5.1 version) at a $5 \%$ significance level. Continuous variables were tested by the Shapiro-Wilk statistic for normal distribution. Normally distributed continuous variables were expressed as the mean \pm standard deviation. Other continuous variables were expressed as the median (interquartile range), and categorical data as counts and percentages. Continuous variables were compared by the Student independent t-test when normally distributed, or by the Mann-Whitney-U test when non-normally distributed. Comparisons of categorical variables between the groups were made using the $\chi^{2}$ test or the Fisher Exact test if expected values were $<5$.

Univariate Cox proportional hazards regression analysis was performed to evaluate which inflammatory cells or clinical parameters were associated with poor mid-term and long-term composite outcome measures after 2-year and 5 -year follow-up. The optimal cut-off point was determined using the receiver operating characteristic (ROC) curve. The Kaplan-Meier analysis was used to compare cumulative survival rates between different subgroups of DCM patients after a 2-year and 5-year follow-up. The log-rank statistic was used to evaluate the statistical significance of differences between the curves.

\section{Results}

\section{Baseline patients' characteristics}

Fifty-seven DCM patients (mean age $47.3 \pm$ \pm 10.9 years; 45 [79\%] males) with chronic heart failure participated in the study. The average LVEDD was $6.8 \pm 0.9 \mathrm{~cm}$, average $\mathrm{LVEF}-26.1 \pm 9.5 \%$, and average pulmonary artery wedge pressure $22 \pm 9 \mathrm{mmHg}$. Of these patients, $41(72 \%)$ were in New York Heart Association (NYHA) III functional class and $10(17 \%)$ were NYHA IV functional class.
The median (interquartile range) heart failure duration was 12 (55) months. Baseline characteristics are shown in Table 2.

Of the 57 patients, 27 (47\%) reached the composite outcome measure during the 5 -year follow-up period: $10(18 \%)$ patients died, $9(16 \%)$ underwent heart transplantation, and 8 (14\%) LV assist device implantation. Other patients remained on conventional medical heart-failure therapy. The 5-year cumulative survival rate was $53 \%$. In univariate Cox regression models, most hemodynamic parameters, echocardiographic parameters and IL-6 were associated with poor clinical outcomes (Table 2).

\section{The prevalence of cardiac inflammation}

Immunohistochemical analysis was performed on 55 endomyocardial biopsies. Myocardial inflammation was detected in 31 of the $55(54 \%)$ DCM patients. Patients were divided into two groups: inflammatory DCM (iDCM) and non-inflammatory DCM (non-iDCM). No difference was observed in baseline characteristics of the two groups $(p>0.05$; Table 2), except for lower systolic blood pressure and higher level of $\mathrm{B}$-type natriuretic peptide $(\mathrm{BNP})$ in the iDCM group ( $\mathrm{p} \leq 0.05)$.

Kaplan-Meier analysis showed no difference between survival curves of patients with iDCM and non-iDCM ( $>$ > 0.05; Fig. 1).

However, univariate Cox regression analysis revealed an association between a higher $\mathrm{CD} 45 \mathrm{ro}+$ cell count in the myocardium and poor mid-term prognosis. Higher CD3+ cell count in the myocardium was associated with poor mid-term and long-term prognosis. This was not the case for CD68+ inflammatory infiltrative cells (Table 3). ROC curves determined the cut-off values for CD3+ and CD45ro+ cells (Fig. 2). The cohort was divided into two groups according to whether their CD3 + and CD45ro + cell counts were above or below the cut-off value ( $13 \mathrm{cells} / \mathrm{mm}^{2}$ and 11.5 cells $/ \mathrm{mm}^{2}$, respectively). Univariate Cox regression analysis showed that cell counts above cut-off values were associated with worse mid-term and long-term clinical outcome (Table 3). Estimation of survival curves demonstrated that patients with CD3 + and CD45ro + cell counts above the cut-off values had lower survival rates (Fig. 3). Lower p-values in survival analysis and higher hazard ratio (95\% confidence interval) in Cox regression analysis revealed that inflammatory cells predict better mid-term than long-term outcomes.

Inflammatory endothelial activation (increased expression of HLA-DR and ICAM [ $\geq 3$ cells/ $\left./ \mathrm{mm}^{2}\right]$ ) was detected by immunohistochemistry in 


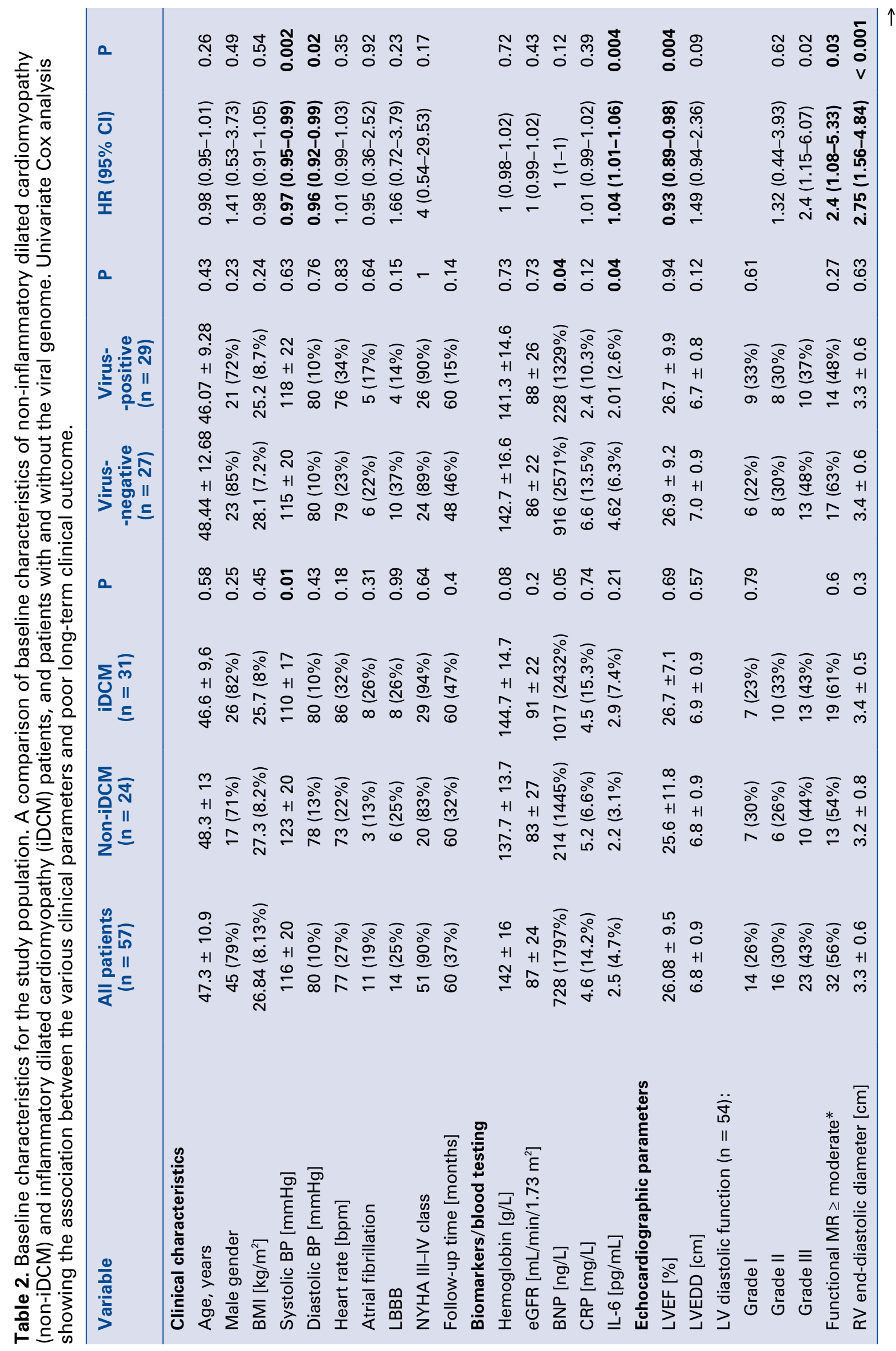




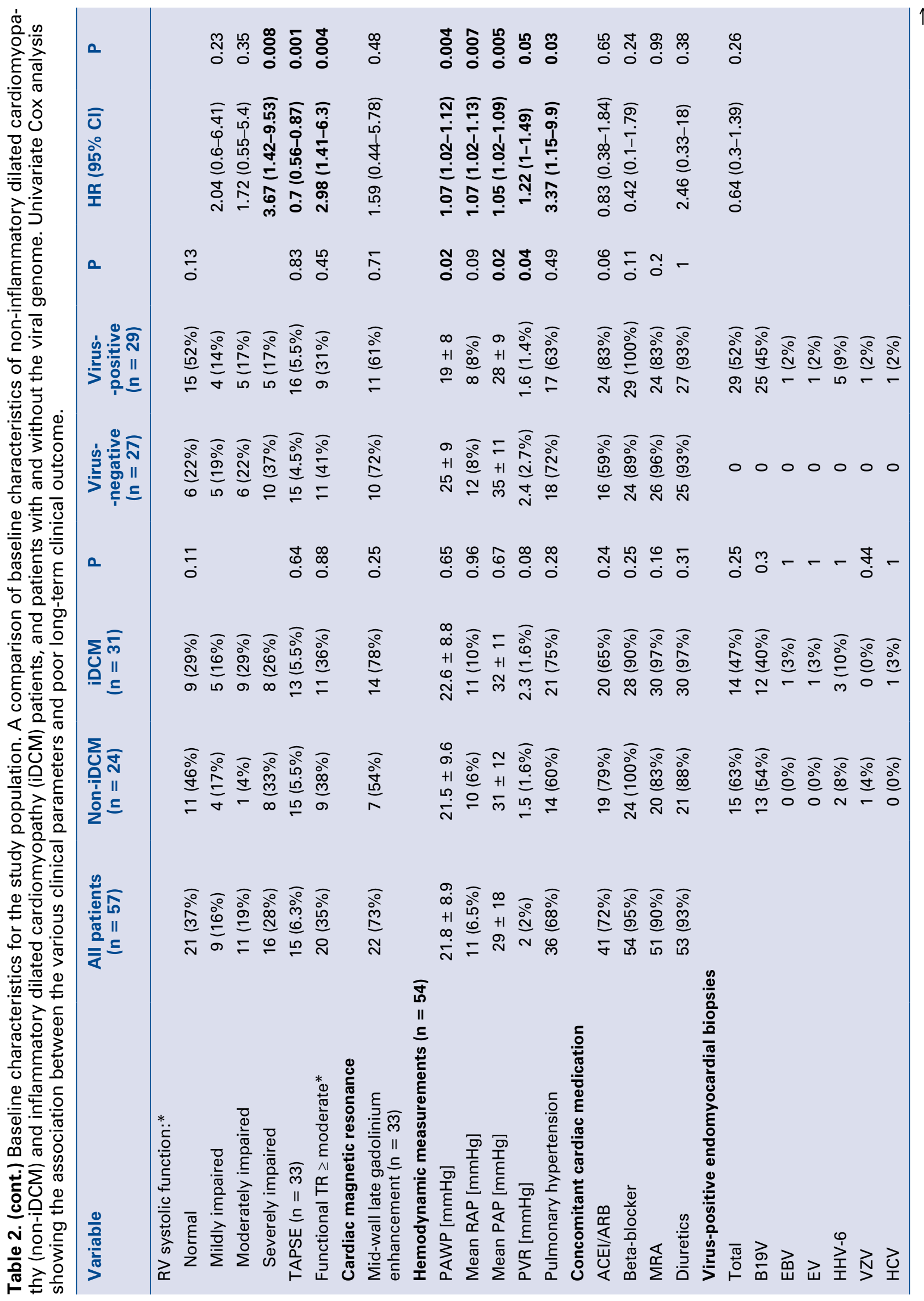



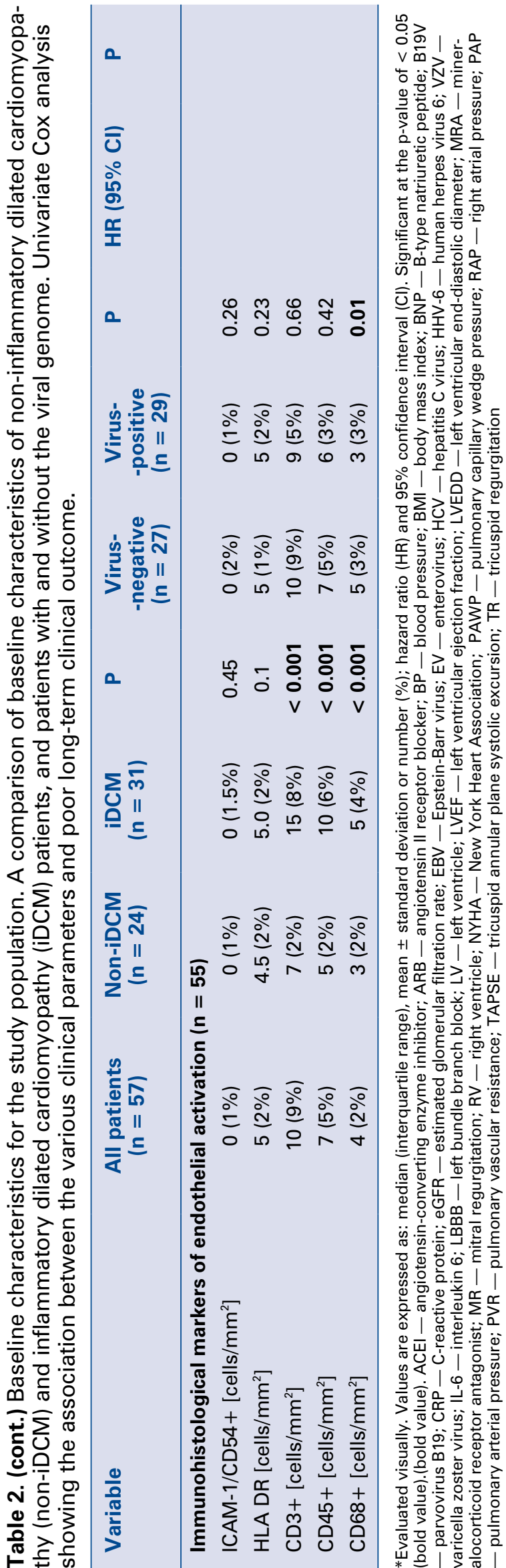

$50(91 \%)$ patients. The expression did not, however, differ between the iDCM and non-iDCM groups $(p>0.05)$. However, it should be interpreted with caution, while these proteins are not only markers for endothelial activation, but are also found on the surface of immune cells.

\section{Prevalence of cardiotropic viruses}

Polymerase chain reaction analysis was performed on 56 endomyocardial biopsies. Viral genomes were detected in the myocardium of 29 (52\%) of the $56 \mathrm{DCM}$ patients. Of these 29 patients, $25(86 \%)$ had the B19V genome, and other $5(17 \%)$ had HHV6 genome. Other viruses (VZV, CMV, EBV, $\mathrm{HCV}, \mathrm{EV})$, were detected in single cases $(\mathrm{n}=1$ [3\%] of each type). Three (10\%) of virus-positive patients had a double infection and one of them (3\%) a triple infection. Co-detection of B19V and HHV6 prevailed ( $\mathrm{n}=3[10 \%])$.

The remaining 27 (48\%) patients were virus-negative. There were no differences in most baseline parameters between the virus-positive and virus-negative groups ( $p>0.05$ ), except for higher BNP and IL-6 levels, worse hemodynamic parameters (Table 2), and a higher number of infiltrative CD68+ cells in the virus-negative group (Fig. 4).

Kaplan-Meier survival curves demonstrated no difference in survival rates of patients in virus-positive and virus-negative groups ( $p>0.05$; Fig. 5).

\section{Sub-groups of idiopathic DCM}

Both PCR analysis and immunohistochemical evaluation were performed on 54 DCM patients. Based on the detection of viral genome - in combination with positive or negative immunohistochemistry - four specific sub-groups of patients were distinguished:

- Virus-positive (chronic) myocarditis (15 [28\%] patients): both cardiotropic virus and myocardial inflammation was present;

- Autoreactive iDCM (16 [30\%] patients): no cardiotropic virus was detected but myocardial inflammation was present;

- Viral DCM (14 [26\%] patients): viral genome was detected but no signs of myocardial inflammation;

- Non-inflammatory DCM (9 [17\%] patients): neither viral genome nor inflammation was detected. 


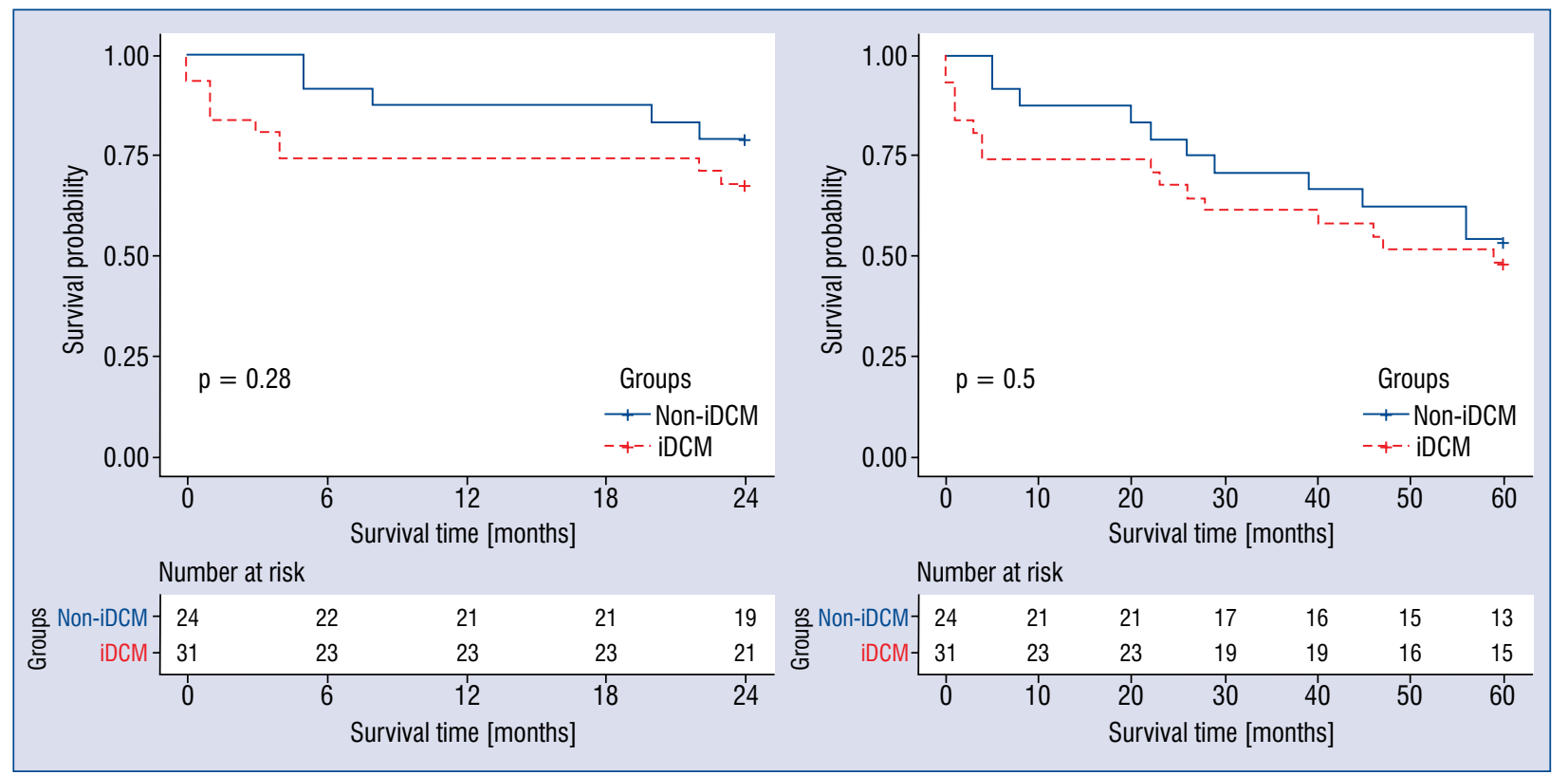

Figure 1. Kaplan-Meier analysis of the inflammatory dilated cardiomyopathy (iDCM) and non-inflammatory dilated cardiomyopathy (non-iDCM) groups.

Table 3. Univariate Cox analysis showing the association between the number of myocardial inflammatory infiltrates and poor clinical outcome after 2-year and 5-year follow-up.

\begin{tabular}{lcccc}
\hline \multirow{2}{*}{$\begin{array}{l}\text { Cardiac inflammatory infiltration } \\
\text { and endothelial activation } \\
\text { markers [cells } / \mathbf{m m}^{2} \text { ] }\end{array}$} & \multicolumn{3}{c}{ HR (95\% CI) } \\
\cline { 2 - 5 } & 2-year follow-up & $\mathbf{P}$ & $\mathbf{5}$-year follow-up & $\mathbf{P}$ \\
\hline CD3+ & $\mathbf{1 . 0 8 5 ( 1 . 0 4 - 1 . 1 3 2 )}$ & $<\mathbf{0 . 0 0 1}$ & $\mathbf{1 . 0 6 1 ( 1 . 0 2 - 1 . 1 0 3 )}$ & $\mathbf{0 . 0 0 3}$ \\
CD45ro+ & $\mathbf{1 . 0 7 9 ( 1 . 0 2 5 - 1 . 1 3 6 )}$ & $\mathbf{0 . 0 0 4}$ & $1.048(0.998-1.101)$ & 0.06 \\
CD68+ & $1.075(0.862-1.34)$ & 0.523 & $1.029(0.867-1.223)$ & 0.74 \\
CD4+- & $1.01(0.91-1.13)$ & 0.82 & $1.013(0.908-0.13)$ & 0.82 \\
CD54+ & $0.82(0.53-1.25)$ & 0.35 & $0.816(0.532-1.254)$ & 0.35 \\
HLA-DR+ & $1.02(0.91-1.14)$ & 0.7 & $1.022(0.915-1.143)$ & 0.7 \\
CD3+ $\geq 13$ cells $/ \mathrm{mm}^{2}$ & $\mathbf{4 . 4 8 1 ( 1 . 5 8 8 - 1 2 . 6 4 )}$ & $\mathbf{0 . 0 0 5}$ & $\mathbf{2 . 1 8 1 ( 1 . 0 0 9 - 4 . 7 1 1 )}$ & $\mathbf{0 . 0 4 7}$ \\
CD45ro+ $\geq 11.5 \mathrm{cells} / \mathrm{mm}^{2}$ & $\mathbf{5 . 2 6 1 ( 1 . 8 5 4 - 1 4 . 9 3 )}$ & $\mathbf{0 . 0 0 2}$ & $\mathbf{2 . 8 9 2 ( 1 . 2 1 7 - 6 . 8 7 1 )}$ & $\mathbf{0 . 0 1 6}$ \\
\hline
\end{tabular}

Values are expressed as hazard ratio (HR) and $95 \%$ confidence interval (Cl). Significant at the $\mathrm{p}$-value of $<0.05$ (bold value).

\section{Discussion}

This prospective study summarizes an experience identifying etiopathogenetic markers of idiopathic DCM for diagnosis of distinct disease sub-entities, and evaluates their prognostic value. In this study, the criterion defined by the ESC Working Group on Myocardial and Pericardial Diseases [1] for diagnosing iDCM was used. iDCM was diagnosed in $54 \%$ of the patients by immunohistochemistry. The rate of the iDCM was similar when compared to the study by Palecek et al. [30].
The prognostic value of myocardial inflammation and different inflammatory cells varies in different studies, possibly due to the diversity of diagnostic protocols [31]. Though, according to available research, we found no study which evaluated the prognostic value of iDCM diagnosed by ESC criterion. In the present cohort, iDCM had no impact on clinical outcomes. However, a higher count of CD3 + and CD45ro + cells were associated with a poor clinical outcome.

The current study found a high prevalence of cardiotropic viruses (52\% of patients), of which 


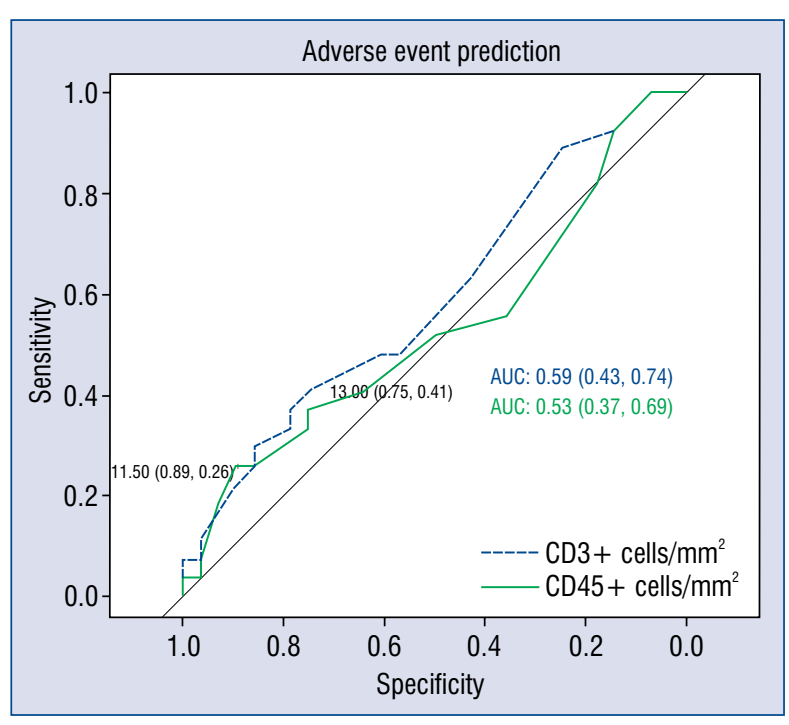

Figure 2. Receiver operating characteristic curve analysis of CD3+ and CD45ro+ cells for predicting composite endpoint. The best cut-off values were 13 CD3+ cells/ $/ \mathrm{mm}^{2}$ (sensitivity, $41 \%$; specificity, $75 \%$ ) and 11.5 CD45ro+ cells $/ \mathrm{mm}^{2}$ (sensitivity, 26\%; specificity, $89 \%$ ).

the most frequently detected were $\mathrm{B} 19 \mathrm{~V}$ and HHV6. Three (10\%) patients were co-infected with B19V and HHV6. These findings support previous studies, in which B19V and HHV6 were the most frequent viruses [10, 32, 33]. Furthermore, the high prevalence of $\mathrm{B} 19 \mathrm{~V}$ suggests that chronic DCM might have developed from the previous B19V-associated myocarditis [34]. However, there is conflicting evidence about the viral genome's impact on the long-term prognosis. Several studies revealed that viral genomes were associated with worsening $\mathrm{LV}$ function, the need for heart transplantation, and death [10,35]. While other studies report that the existence of viral genomes per se is not associated with poor clinical outcome $[12,36-38]$. In the present cohort, detection of a virus had no impact on clinical outcome.

However, half of the virus-positive patients had no myocardial inflammation. This finding is also reported by Kühl et al. [10], in whose study DCM patients had symptoms of heart failure and viral genome, but no evidence of inflammation. Kindermann et al. [12] have also reported that the frequency of inflammation is independent of any evidence of the virus genome. Several studies detected B19V in healthy people's hearts with no evidence of inflammation [38-40].

In contrast, half of the current iDCM patients had no viral genome, and cause of inflammation remains unknown. This finding supports the idea that myocardial inflammation could be maintained by an autoimmune process leading to the deterioration of LV function [41]. Contrarily, this high prevalence of cardiac inflammation might be due to the advanced DCM phenotype. The question remains whether this inflammation is a consequence of this advanced stadium or if it acts as a causal factor.

Interestingly, the macrophage count was higher in the virus-negative group. It could be hypothesized that CD68+ macrophages have an impact on DCM pathogenesis because of their pro-inflammatory activity. As known from previous studies, macrophages can cause or maintain persistent LV systolic dysfunction and LV remodeling [42]. While recent studies have noted the importance of macrophage profiles and their function in heart diseases, much is still unknown about their impact on DCM pathogenesis [43].

Virus-negative patients had worse hemodynamic parameters and higher BNP levels than the virus-positive patients, although echocardiographic parameters did not differ between the two groups. Worse hemodynamic status might be explained by chronic immune activation and myocardial inflammation, given that higher numbers of macrophages and higher levels of IL- 6 were detected in this virus-negative group. Macrophages secrete IL-6 [44], which might increase the severity of pulmonary hypertension [45].

Although heart failure treatment has become more effective, there are still many refractory DCM patients who do not respond to any available treatment. Therefore, developing alternative therapies is essential. Four etiopathogenetic groups were distinguished, for whom the specific therapeutic strategy selected could be suitable $[1,6,46]$ or novel treatment options established [13]. Treatment strategies based on the etiopathogenetic approach to the disease might improve LV function, prevent progression of heart failure, and, in some cases, exclude patients from the heart transplant list.

\section{Limitations of the study}

First, small sample size did not allow for differentiation of patients based on the type of infectious agent. Second, the study had no control group, due to a shortage of healthy donor hearts which were not suitable for transplantation. Third, as a result of financial considerations, neither virus replication nor the viral load for distinguishing active from incidental infection were investigated [47], nor was autoantibody testing performed or genetic screening for pathogenic DCM mutations. Fourth, due to limited-experience in specific DCM treatment and 


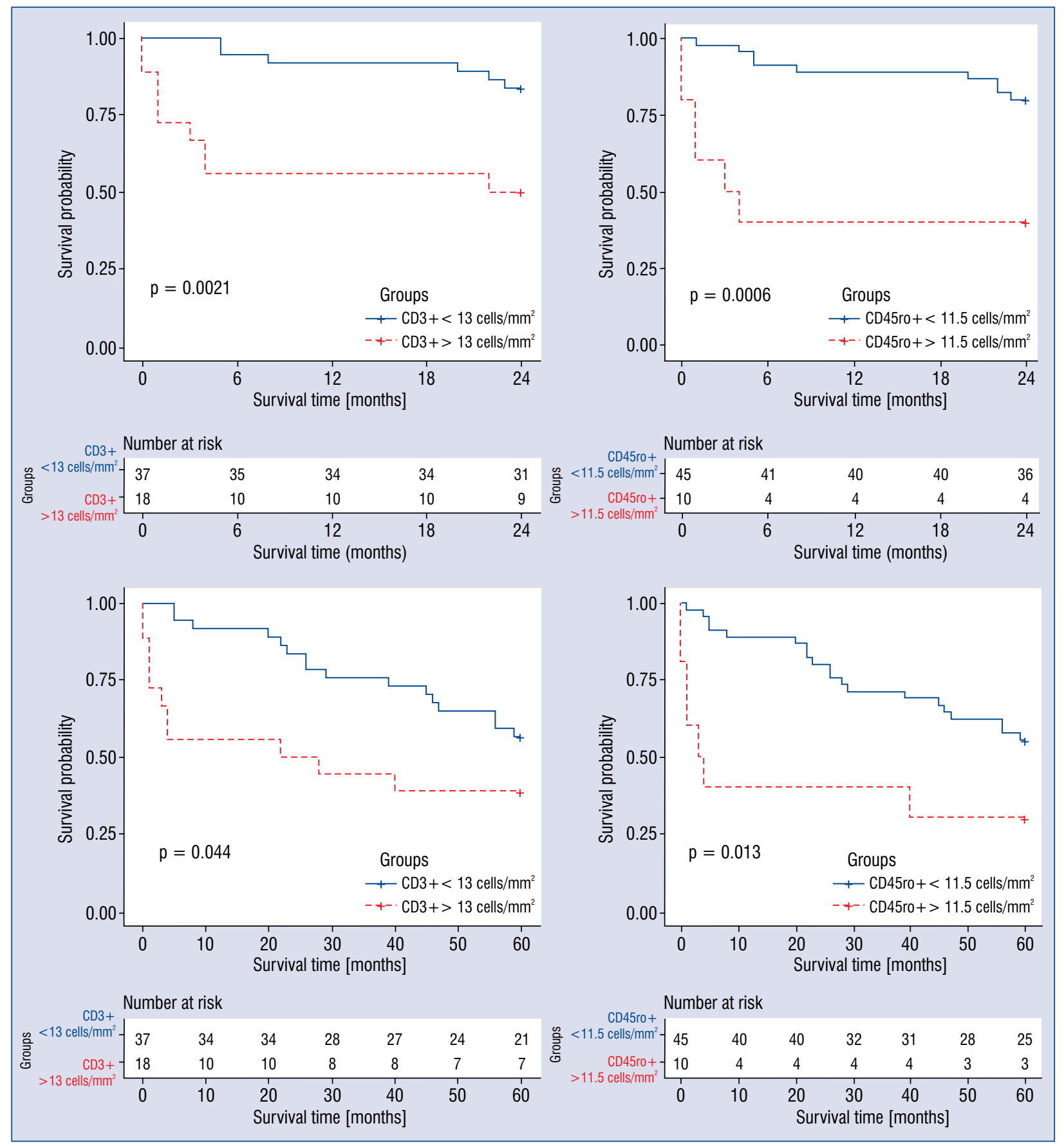

Figure 3. Survival curves according to the count of CD3+ and CD45ro+ cells. Patient groups with a higher number of infiltrative cells $\left(\mathrm{CD} 3+>13\right.$ cells $/ \mathrm{mm}^{2}$ and CD45ro $+>11.5$ cells $/ \mathrm{mm}^{2}$ ) had a significantly lower survival rate than groups with lower cell counts.

the treatment costs, none of the patients received etiology-directed treatment. Finally, the study was held at a time when right ventricle was a "forgotten" ventricle, therefore it was limitedly assessed. In spite of its limitations, the study certainly provides a basis for a more extensive diagnostic and treatment studies - based on etiopathogenetic sub-entities which include a control group.

\section{Conclusions}

This study has shown that two markers, cardiotropic viruses and myocardial inflammation, are prevalent among DCM patients and are helpful in identifying sub-groups of DCMs. An increased number of T-lymphocytes in the myocardium is a predictor of poor mid-term and long-term 


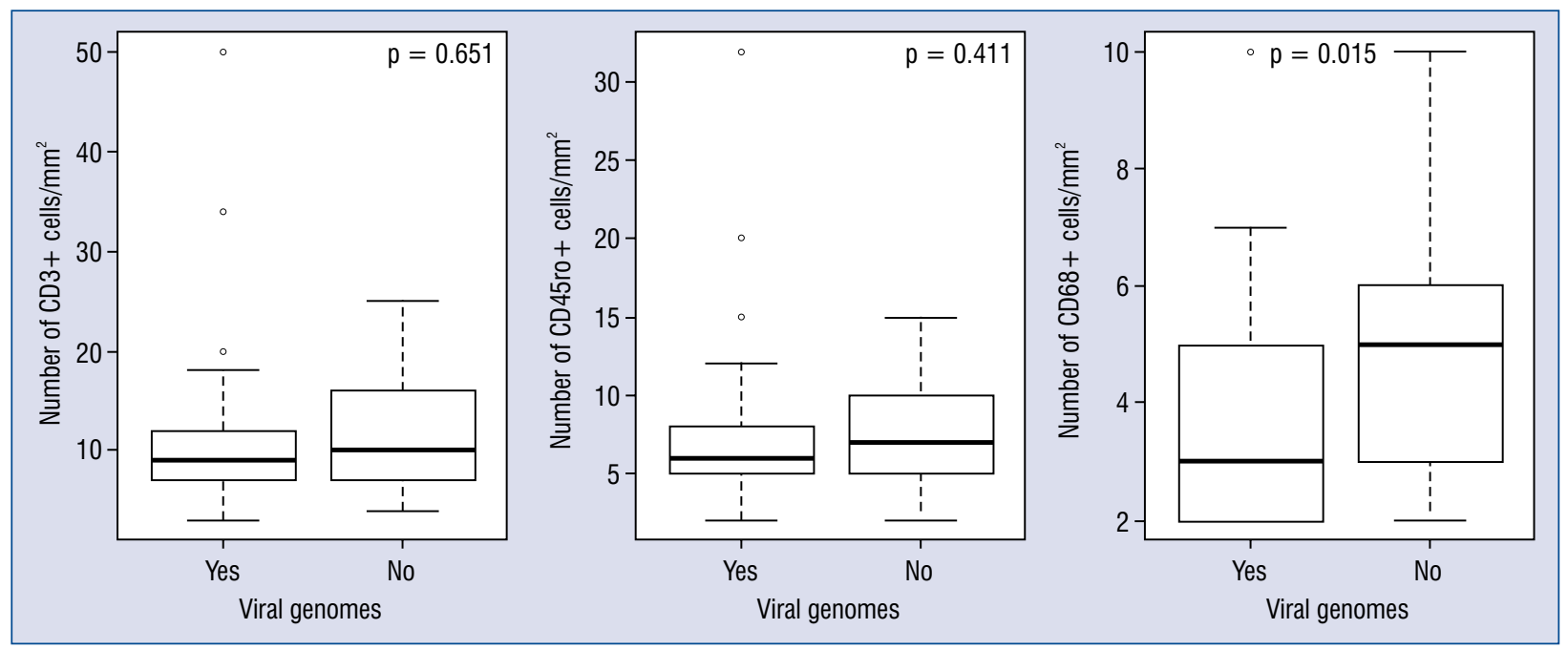

Figure 4. Comparison of inflammatory cell (CD3+, CD45ro+, and CD68+) counts in the virus-negative and virus-positive biopsies.

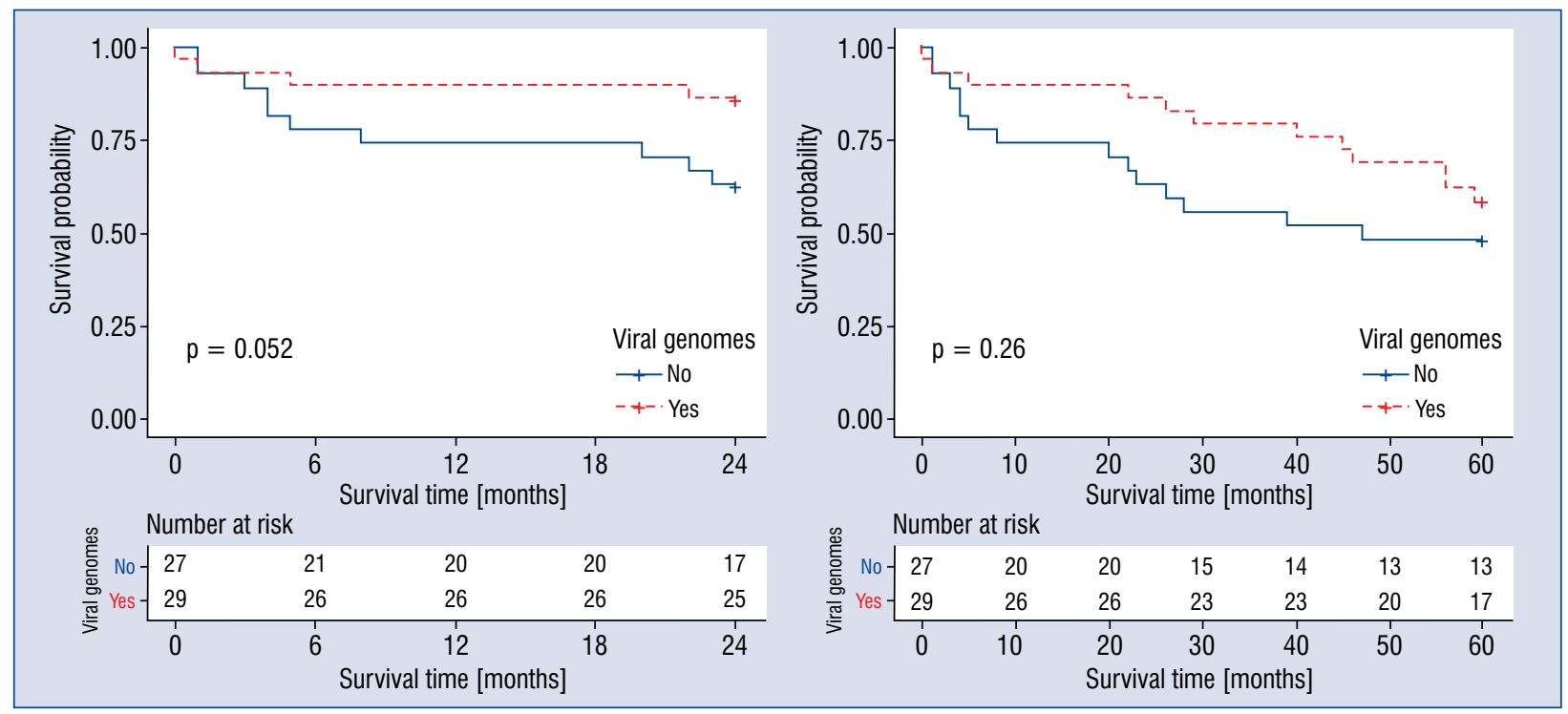

Figure 5. The Kaplan-Meier curves for virus-positive and virus-negative groups.

prognosis. The finding of specific inflammatory cells as a prognostic marker could be of value in determining new definitions of cardiac inflammation. A natural continuation of this work would be further analysis of specific etiologic DCM subgroups and a search for etiology-directed treatment strategies.

\section{Acknowledgments}

The study was supported by the Research Council of Lithuania (Grants no. MIP-086/2012 and MIP-011/2014), the European Union, EU-FP7, SARCOSI Project (no. 291834).

Conflict of interest: Jelena Čelutkiné — personal fees from: Novartis, Roche Diagnostics, Servier, AstraZeneca, outside the submitted work.

\section{References}

1. Caforio ALP, Pankuweit S, Arbustini E, et al. Current state of knowledge on aetiology, diagnosis, management, and therapy of 
myocarditis: a position statement of the European Society of Cardiology Working Group on Myocardial and Pericardial Diseases. Eur Heart J. 2013; 34(33): 2636-2648, doi: 10.1093/eurheartj/ eht210, indexed in Pubmed: 23824828.

2. Elliott P, Andersson B, Arbustini E, et al. Classification of the cardiomyopathies: a position statement from the European Society Of Cardiology Working Group on Myocardial and Pericardial Diseases. Eur Heart J. 2008; 29(2): 270-276, doi: 10.1093/eurheartj/ ehm342, indexed in Pubmed: 17916581.

3. Chambers DC, Cherikh WS, Goldfarb SB, et al. The International Thoracic Organ Transplant Registry of the International Society for Heart and Lung Transplantation: Thirty-fifth adult lung and heartlung transplant report-2018; Focus theme: Multiorgan Transplantation. J Heart Lung Transplant. 2018; 37(10): 1169-1183, doi: 10.1016/j.healun.2018.07.020, indexed in Pubmed: 30293613.

4. Richardson P, McKenna W, Bristow M, et al. Report of the 1995 World Health Organization/International Society and Federation of Cardiology Task Force on the Definition and Classification of cardiomyopathies. Circulation. 1996; 93(5): 841-842, doi: 10.1161/01.cir.93.5.841, indexed in Pubmed: 8598070.

5. Maisch B, Portig I, Ristic A, et al. Definition of inflammatory cardiomyopathy (myocarditis): on the way to consensus. A status report. Herz. 2000; 25(3): 200-209, doi: 10.1007/s000590050007, indexed in Pubmed: 10904839.

6. Pinto YM, Elliott PM, Arbustini E, et al. Proposal for a revised definition of dilated cardiomyopathy, hypokinetic non-dilated cardiomyopathy, and its implications for clinical practice: a position statement of the ESC working group on myocardial and pericardial diseases. Eur Heart J. 2016; 37(23): 1850-1858, doi: 10.1093/ eurheartj/ehv727, indexed in Pubmed: 26792875.

7. Cooper L, Baughman K, Feldman A, et al. The Role of Endomyocardial Biopsy in the Management of Cardiovascular Disease. J Am Coll Cardiol. 2007; 50(19): 1914-1931, doi: 10.1016/j. jacc.2007.09.008.

8. Caforio ALP, Calabrese F, Angelini A, et al. A prospective study of biopsy-proven myocarditis: prognostic relevance of clinical and aetiopathogenetic features at diagnosis. Eur Heart J. 2007; 28(11): 1326-1333, doi: 10.1093/eurheartj/ehm076, indexed in Pubmed: 17493945.

9. Aretz HT, Billingham ME, Edwards WD, et al. Myocarditis. A histopathologic definition and classification. Am J Cardiovasc Pathol. 1987; 1(1): 3-14, indexed in Pubmed: 3455232.

10. Kühl U, Pauschinger M, Noutsias M, et al. High prevalence of viral genomes and multiple viral infections in the myocardium of adults with "idiopathic" left ventricular dysfunction. Circulation. 2005; 111(7): 887-893, doi: 10.1161/01. CIR.0000155616.07901.35, indexed in Pubmed: 15699250.

11. Mahrholdt H, Wagner A, Deluigi CC, et al. Presentation, patterns of myocardial damage, and clinical course of viral myocarditis. Circulation. 2006; 114(15): 1581-1590, doi: 10.1161/CIRCULATIONAHA.105.606509, indexed in Pubmed: 17015795.

12. Kindermann I, Kindermann M, Kandolf R, et al. Predictors of outcome in patients with suspected myocarditis. Circulation. 2008; 118(6): 639-648, doi: 10.1161/CIRCULATIONAHA.108.769489, indexed in Pubmed: 18645053.

13. Van Linthout S, Tschöpe C. Viral myocarditis: a prime example for endomyocardial biopsy-guided diagnosis and therapy. Curr Opin Cardiol. 2018; 33(3): 325-333, doi: 10.1097/ HCO.0000000000000515, indexed in Pubmed: 29528906.

14. Cooper L. Myocarditis. N Engl J Med. 2009; 360(15): 1526-1538, doi: $10.1056 /$ nejmra0800028.
15. D’Ambrosio A, Patti G, Manzoli A, et al. The fate of acute myocarditis between spontaneous improvement and evolution to dilated cardiomyopathy: a review. Heart. 2001; 85(5): 499-504, doi: 10.1136/heart.85.5.499, indexed in Pubmed: 11302994.

16. Kühl U, Noutsias M, Seeberg B, et al. Immunohistological evidence for a chronic intramyocardial inflammatory process in dilated cardiomyopathy. Heart. 1996; 75(3): 295-300, doi: 10.1136/ hrt.75.3.295, indexed in Pubmed: 8800996.

17. Hunt S, Baker D, Chin M, et al. ACC/AHA guidelines for the evaluation and management of chronic heart failure in the adult: executive summary. J Am Coll Cardiol. 2001; 38(7): 2101-2113, doi: 10.1016/s0735-1097(01)01683-7.

18. Mueller KAL, Patzelt J, Sauter M, et al. Myocardial expression of the anaphylatoxin receptor $\mathrm{C} 3 \mathrm{aR}$ is associated with cardiac inflammation and prognosis in patients with non-ischaemic heart failure. ESC Heart Fail. 2018; 5(5): 846-857, doi: 10.1002/ ehf2.12298, indexed in Pubmed: 30168657.

19. Nakayama T, Sugano Y, Yokokawa T, et al. Clinical impact of the presence of macrophages in endomyocardial biopsies of patients with dilated cardiomyopathy. Eur J Heart Fail. 2017; 19(4): 490-498, doi: 10.1002/ejhf.767, indexed in Pubmed: 28217949.

20. Escher F, Kühl U, Lassner D, et al. Presence of perforin in endomyocardial biopsies of patients with inflammatory cardiomyopathy predicts poor outcome. Eur J Heart Fail. 2014; 16(10): 1066-1072, doi: 10.1002/ejhf.148, indexed in Pubmed: 25163698.

21. Katzmann JL, Schlattmann P, Rigopoulos AG, et al. Meta-analysis on the immunohistological detection of inflammatory cardiomyopathy in endomyocardial biopsies. Heart Fail Rev. 2020; 25(2): 277-294, doi: 10.1007/s10741-019-09835-9, indexed in Pubmed: 31396762.

22. Henry WL, Gardin JM, Ware JH. Echocardiographic measurements in normal subjects from infancy to old age. Circulation. 1980; 62(5): 1054-1061, doi: 10.1161/01.cir.62.5.1054, indexed in Pubmed: 7418156.

23. Mestroni L, Maisch B, McKenna WJ, et al. Guidelines for the study of familial dilated cardiomyopathies. Collaborative Research Group of the European Human and Capital Mobility Project on Familial Dilated Cardiomyopathy. Eur Heart J. 1999; 20(2): 93-102, doi: 10.1053/euhj.1998.1145, indexed in Pubmed: 10099905.

24. Dickstein K, Cohen-Solal A, Filippatos G, et al. ESC guidelines for the diagnosis and treatment of acute and chronic heart failure 2008: the Task Force for the diagnosis and treatment of acute and chronic heart failure 2008 of the European Society of Cardiology. Developed in collaboration with the Heart Failure Association of the ESC (HFA) and endorsed by the European Society of Intensive Care Medicine (ESICM). Eur J Heart Fail. 2008; 10(10): 933-989, doi: 10.1016/j.ejheart.2008.08.005, indexed in Pubmed: 18826876.

25. McMurray JJV, Adamopoulos S, Anker SD, et al. ESC Guidelines for the diagnosis and treatment of acute and chronic heart failure 2012: The Task Force for the Diagnosis and Treatment of Acute and Chronic Heart Failure 2012 of the European Society of Cardiology. Developed in collaboration with the Heart Failure Association (HFA) of the ESC. Eur Heart J. 2012; 33(14): 1787-1847, doi: 10.1093/eurheartj/ehs104, indexed in Pubmed: 22611136.

26. Baltrūnienė V, Bironaitė $\mathrm{D}$, Kažukauskienè I, et al. The role of serum adiponectin for outcome prediction in patients with dilated cardiomyopathy and advanced heart failure. Biomed Res Int. 2017; 2017: 3818292, doi: 10.1155/2017/3818292, indexed in Pubmed: 29318144.

27. Noutsias M, Seeberg B, Schultheiss HP, et al. Expression of cell adhesion molecules in dilated cardiomyopathy: evidence for en- 
dothelial activation in inflammatory cardiomyopathy. Circulation. 1999; 99(16): 2124-2131, doi: 10.1161/01.cir.99.16.2124, indexed in Pubmed: 10217652.

28. Allard A, Albinsson B, Wadell G. Rapid typing of human adenoviruses by a general PCR combined with restriction endonuclease analysis. J Clin Microbiol. 2001; 39(2): 498-505, doi: 10.1128/ JCM.39.2.498-505.2001, indexed in Pubmed: 11158096.

29. McIver CJ, Jacques CFH, Chow SSW, et al. Development of multiplex PCRs for detection of common viral pathogens and agents of congenital infections. J Clin Microbiol. 2005; 43(10): 5102-5110, doi: 10.1128/JCM.43.10.5102-5110.2005, indexed in Pubmed: 16207970.

30. Palecek T, Kuchynka P, Hulinska D, et al. Presence of Borrelia burgdorferi in endomyocardial biopsies in patients with newonset unexplained dilated cardiomyopathy. Med Microbiol Immunol. 2010; 199(2): 139-143, doi: 10.1007/s00430-009-0141-6, indexed in Pubmed: 20052487.

31. Katzmann JL, Schlattmann P, Rigopoulos AG, et al. Meta-analysis on the immunohistological detection of inflammatory cardiomyopathy in endomyocardial biopsies. Heart Fail Rev. 2020; 25(2): 277-294, doi: 10.1007/s10741-019-09835-9, indexed in Pubmed: 31396762.

32. Pankuweit S, Portig I, Eckhardt H, et al. Prevalence of viral genome in endomyocardial biopsies from patients with inflammatory heart muscle disease. Herz. 2000; 25(3): 221-226, doi: 10.1007/s000590050010, indexed in Pubmed: 10904842.

33. Verdonschot J, Hazebroek M, Merken J, et al. Relevance of cardiac parvovirus B19 in myocarditis and dilated cardiomyopathy: review of the literature. Eur J Heart Fail. 2016; 18(12): 1430-1441, doi: 10.1002/ejhf.665, indexed in Pubmed: 27748022.

34. Maisch B, Richter A, Sandmöller A, et al. BMBF-Heart Failure Network. Inflammatory dilated cardiomyopathy (DCMI). Herz. 2005; 30(6): 535-544, doi: 10.1007/s00059-005-2730-5, indexed in Pubmed: 16170686.

35. Kühl U, Pauschinger M, Seeberg B, et al. Viral persistence in the myocardium is associated with progressive cardiac dysfunction. Circulation. 2005; 112(13): 1965-1970, doi: 10.1161/CIRCULATIONAHA.105.548156, indexed in Pubmed: 16172268.

36. Nowalany-Kozielska E, Kozieł M, Domal-Kwiatkowska D, et al. Clinical significance of viral genome persistence in the myocardium of patients with dilated cardiomyopathy. Intervirology. 2015; 58(6): 350-356, doi: 10.1159/000443375, indexed in Pubmed: 26845221.

37. Kuethe F, Sigusch HH, Hilbig K, et al. Detection of viral genome in the myocardium: lack of prognostic and functional relevance in patients with acute dilated cardiomyopathy. Am Heart J. 2007; 153(5): 850-858, doi: 10.1016/j.ahj.2007.02.013, indexed in Pubmed: 17452164 .

38. Lotze U, Egerer R, Glück B, et al. Low level myocardial parvovirus B19 persistence is a frequent finding in patients with heart disease but unrelated to ongoing myocardial injury. J Med Virol. 2010; 82(8): 1449-1457, doi: 10.1002/jmv.21821, indexed in Pubmed: 20572082.

39. Schenk T, Enders M, Pollak S, et al. High prevalence of human parvovirus B19 DNA in myocardial autopsy samples from subjects without myocarditis or dilative cardiomyopathy. J Clin Microbiol. 2009; 47(1): 106-110, doi: 10.1128/JCM.01672-08, indexed in Pubmed: 19005147.

40. Corcioli F, Zakrzewska K, Rinieri A, et al. Tissue persistence of parvovirus B19 genotypes in asymptomatic persons. J Med Virol. 2008; 80(11): 2005-2011, doi: 10.1002/jmv.21289, indexed in Pubmed: 18814251.

41. Kawai C. From myocarditis to cardiomyopathy: mechanisms of inflammation and cell death: learning from the past for the future. Circulation. 1999; 99(8): 1091-1100, doi: 10.1161/01. cir.99.8.1091, indexed in Pubmed: 10051305.

42. Bajpai G, Schneider C, Wong N, et al. The human heart contains distinct macrophage subsets with divergent origins and functions. Nat Med. 2018; 24(8): 1234-1245, doi: 10.1038/s41591018-0059-x, indexed in Pubmed: 29892064.

43. Lavine KJ, Pinto AR, Epelman S, et al. The Macrophage in Cardiac Homeostasis and Disease: JACC Macrophage in CVD Series (Part 4). J Am Coll Cardiol. 2018; 72(18): 2213-2230, doi: 10.1016/j.jacc.2018.08.2149, indexed in Pubmed: 30360829.

44. Hilgendorf I, Gerhardt LMS, Tan TC, et al. Ly-6Chigh monocytes depend on Nr4a1 to balance both inflammatory and reparative phases in the infarcted myocardium. Circ Res. 2014; 114(10): 1611-1622, doi: 10.1161/CIRCRESAHA.114.303204, indexed in Pubmed: 24625784.

45. Steiner MK, Syrkina OL, Kolliputi N, et al. Interleukin-6 overexpression induces pulmonary hypertension. Circ Res. 2009; 104(2): 236-244, doi: 10.1161/CIRCRESAHA.108.182014, indexed in Pubmed: 19074475.

46. Tschöpe C, Elsanhoury A, Schlieker S, et al. Immunosuppression in inflammatory cardiomyopathy and parvovirus B19 persistence. Eur J Heart Fail. 2019; 21(11): 1468-1469, doi: 10.1002/ ejhf.1560, indexed in Pubmed: 31476088.

47. Bock CT, Klingel K, Kandolf R. Human parvovirus B19-associated myocarditis. N Engl J Med. 2010; 362(13): 1248-1249, doi: 10.1056/NEJMc0911362, indexed in Pubmed: 20357294. 